\title{
Onfalocele, Divertículo de Meckel Permeable y Trisomía 13
}

\author{
Dr. Sergio Zúnitiga R. ${ }^{2}$; Dr. Andrés Maira E. ${ }^{2}$; Dr. Alejandro Zavala B. ${ }^{2}$ \\ Omphalocele, Permeable Meckel's Diverticulum and 13 Trisomy \\ Case Report
}

\begin{abstract}
A newborn with 13 Trisomy Syndrome, omphalocele and patent Meckel's diverticulum (patent omphalomesenteric duct) is described. This association has been published previously only once: lt is pastulated that it could be another, infrequent, aspect of the Patau's Syndrome or 13 Trisomy Syndrome.

(Key words: 13 Trisomy. Patau's Sydrome. Omphalocele. Patent omphalomesenteric duct. Meckel's diverticulum).
\end{abstract}

El onfalocele (exónfalo, amniocele) es una malformación que se reconoce con facilidad en el neonato. Una membrana transparente cubre un defecto de tamaño variable de la pared abdominal y contiene vísceras, las que, pueden ser visualizadas a través de ella. El cordón umbilical se origina en el ápice o en la superficie inferior de la membrana, según el tamaño del onfalocele ${ }^{3}, 5$.

La rotura de un onfalocele al nacer o en el tiempo siguiente, constituye una emergencia que requiere tratamiento quirúrgico inmediato. Exissten. sin embargo, algunas situaciones que pueden simular un onfalocele roto, como en el siguiente caso.

\section{Caso Clínico}

Un recién nacido, de 8 horas de vida, producto de un embarazo de término, parto eutódico, peso 2.630 gr. al nacer y padres sanos, fue trasladado desde una matemidad al Servicio de Urgencia del Hospital Dr. Exequiel González Cortés con diagnóstico de malformaciones múltiples y onfalocele roto.

En el examen físico de ingreso se encontró hipertelorismo, agenesia de pabellón auricular

1. Servicio Cirugia Pediátrica. Hospital Exequiel González Cortés. Div. Ciencias Médicas Sur, Facultad de Medicina. Universidad de Chile.

2. Becado Servicio Cirugía Pediátrica. Hospita] Exequiel González Cortés. Div. Ciencias Médicas Sur. Facultad de Medicina. Universidad de Chile. derecho, labio leporino bilateral con fisura palatina, polidactilia de ambas extremidades superiores y pie derecho, criptorquidea bilateral. En el abdomen, había un onfalocele de $8 \mathrm{~cm}$ de diámetro que en la superficie inferior presentaba una estructura con aspecto de "caracol" (Figs. ] y 2) por la que se eliminaba meconio en dos puntos.

Los elementos del examen físico descritos permitían sospechar una trisomía del cromosoma 13 , como fue confirmado posteriormente por el cariograma (Fig. 3).

En la intervención quiruirgica el onfalocele estaba intacto y la estructura correspondía a un divertículo de Meckel permeable (fístula onfalomesentérica) prolapsado (Fig. 4) que se extirpó, realizándose anastómosis intestinal y reparación de la pared abdominal en un tiempo, según técnica de Gross.

La evolución postoperatoria del niño fue satisfactoria, con buen tránsito intestinal desde el tercer día de operado. Más adelante, una infec. ción bacteríana de origen pulmonar complicó su evolución, falleciendo a los 35 días de vida.

En la necropsia, además de los hechos mencionados se comprobó que el ductus arterioso estaba permeable, que había bronconeumonia e hidropionefrosis, ambas bilaterales.

\section{COMENTARIO}

Entre las varias malformaciones congénitas que pueden presentarse en un recién nacido, la 


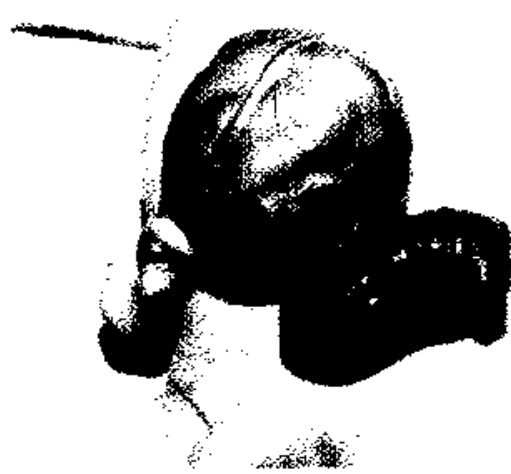

Fura 1: Aspecto del untalocele oun el divertículo dL Meckel prolapsado en su superficie inferior

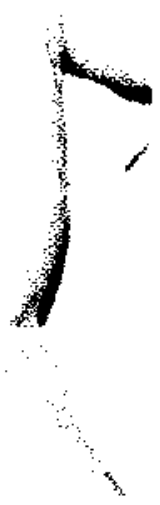

Figurz 2: Diverticula de Mockel peruncable probapsado (uspecto de earacoil).

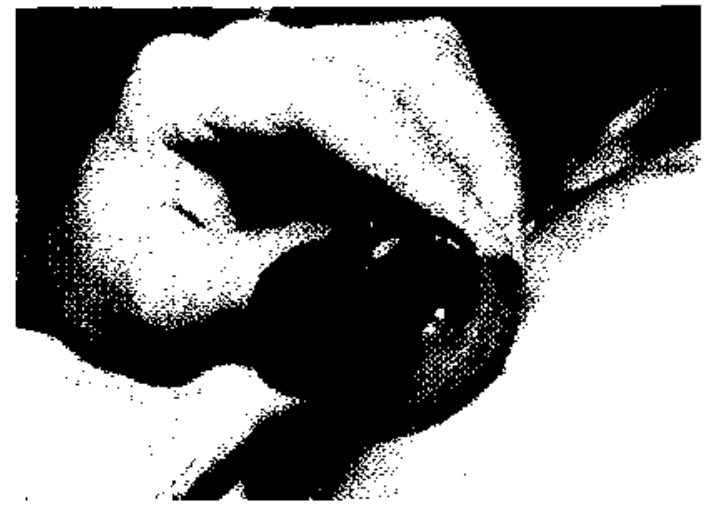

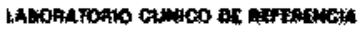

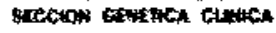

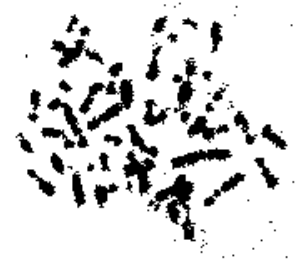

\section{Captortion}
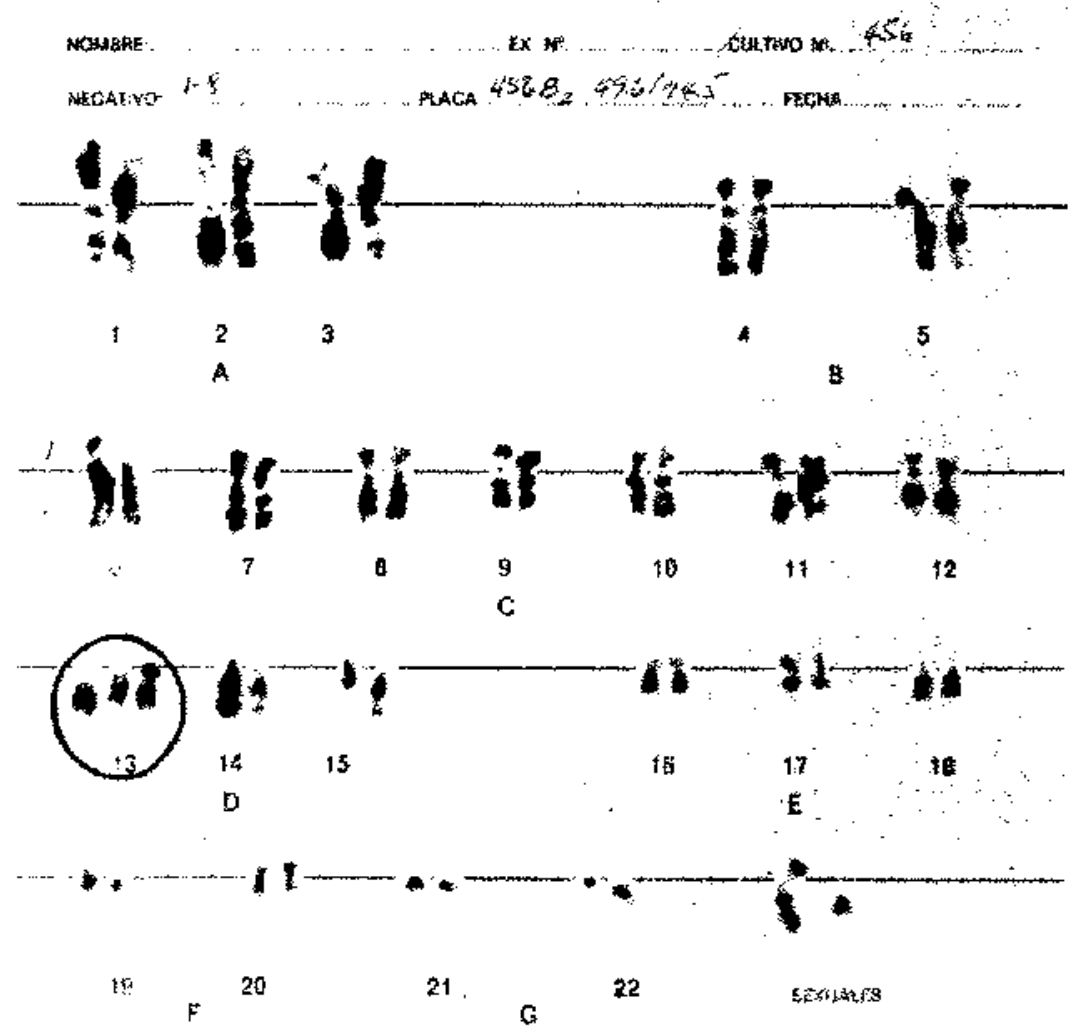

Figura 3: Cariograma que muestra trisomía del cromosoma 13. 


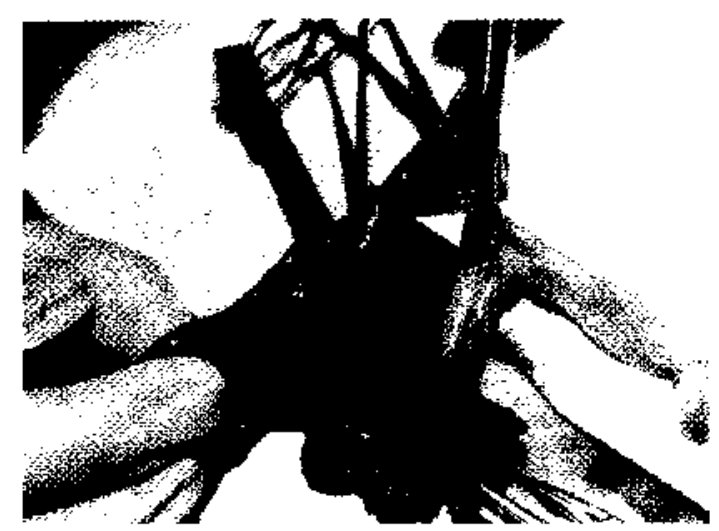

Figura 4: Aspecto de la intervención. La flecha indica la fístula onfalomesentérica o divertículo de Meckel permeable.

coexistencia de onfalocele y un diverticulo de Meckel permeable ofístula onfalomesentérica, es rara. Escasos autores la mencionan ${ }^{5}, 6$ y aparentemente no se conoce su frecuencia, liasta el momento. En cambio está descrito que, habitualmente, la situación es confundida con un onfalocele roto en la primera inspección ${ }^{5}$, como ocurrió en este caso que, además del defecto de la pared abdominal, era portador de un síndrome de Patau o trisomia del cromosoma 13. Sólo un caso publicado anteriormente ${ }^{6}$ presentaba la misma asociación.

El síndrome de trisomía 13 se asocia con onfalocele en un 10 a $20 \%$ y con diverticulo de Meckel, también entre un 10 a $20 \%$ de los casos ${ }^{1}$. 2, 4, 7. La frecuencia de asociación de las.tres entidades y además con el divertículo permeable, no ha sido publicada. Asi, este caso, junto con otro mencionado en la literatura ${ }^{6}$ podrían sugerir que esta asociaciôn fuese otro rasgo fenotípico más de la trisomía $\mathbf{3} 3$.

\section{RESUMEN}

Se describe un recién nacido con trisomía del cromosoma 13, onfalocele y divertículo de Meckel permeable o fístula onfalomesentérica. Está asociación ha sido descrita sólo en una oportunidad anteriormente. Se postula que podría constituir una característica más del sindrome de Patau o trisomia del cromosoma 13.

\section{AGRADECIMIENTOS}

Los autores agradecen al Servicio de Nconatología del Hospital Ramón Barros Luco-Trudeau y el Dr. Ives Lacassie, Jefe del Depto. Genética de INTA.

\section{REFERENCIAS}

1. Bergsma D.: Birth Defects Compendium. 2a. Ed. N.Y. 1979. The National Foundation. March of Dimes 1979. Pág. 212-213.

Editorial. F1 síndrome de Patau: Actualidad Pediá-

2. trica. 36: 101, 1969.

3. Gray S.W., Skandalakis J.E.: A nomalías Congénitas (Embriogénesis, diagnóstico y tratamiento) Ed. Pediátrica, Barcelona 1975. Pág. 434-439.

4. Moraine $C$., Laugier $J$., Grenier B. et Desbuquois $G$.: Trisomie 13 алл Pediatr. 19: 405. 1972.

5. Rickhmon P.P., Lisfer J., Irving I.M.: Neonatal Surgery. 2a Ed. Butterworths, London 1978. Pág. $309-333$.

6. Scwartz D.L., Citron P., Becker J.M.: Correspondence J. Pediatr. Surg. 19:617, 1984.

7. Smith D.W.: Atlas de Malformaciones Somáticas en el niño. Ed. Pediátrica, Barcelona 1972. Pág. 42-43. 